\section{High-energy physics}

\section{Support grows in Hamburg}

IN one of the more extraordinary campaigns of the German election last Sunday, parties in Hamburg were falling over themselves to support big science - in the shape of a major new accelerator for the Deutsches Elektronen-synchrotron laboratory.

DESY (as the laboratory is called) sits smack in the middle of a Hamburg suburb, and has successfully courted the support of the Social Democrat city fathers - who pay 10 per cent of the DESY budget - for many a year. But this year, DESY benefited from the more than 1,000 jobs that its next project - a $30-\mathrm{GeV}$ on $820 \mathrm{GeV}$ electronproton collider called HERA - is destined to bring Hamburg for the seven years of its construction. The Social Democrats (like everyone, no doubt, short of ideas for job creation) raised their support of HERA as a campaign issue, and the Christian Democratic Union followed suit.

In fact, the Christian Democrat science minister in Bonn, Dr Heinz Riesenhuber, went further: he made a commitment "in principle"' that the HERA project will start in 1984.

The provisos are that Hamburg will pick up 15 per cent (rather than the usual 10 per cent) of the DM 300 million ( $\$ 81$ million) rise in the estimated price of HERA since it was mooted a few years ago (it will now cost DM 960 million, or around $£ 260$ million); and that there will be "sufficient" support from foreign countries.

Hamburg has already agreed to the 15 per cent. Sufficient foreign support has not been defined, but it could mean something of the order of a quarter the cost of HERA coming in the form of materials and equipment from countries such as France, Italy and Canada - which have been showing a strong interest in the project. Riesenhuber's firm statement will now enable supporters of HERA in these countries to take the matter further politically. DESY management is hoping that its supporters will move fast: the German budget for 1984 will be decided in June, and commitments from foreign partners will be needed by then if HERA is to start next January. Then the $6.3 \mathrm{~km}$ tunnel would be dug (under local houses) using conventional sewer-building technology. Seven years later HERA should give a beam, making possible a detailed survey of the structure of the proton, using the point-like electron as a precise probe rather as Rutherford used alpha particles to probe the atom.

The programme, however, depends on the successful development of superconducting bending magnets to keep the highenergy protons on course - a technology that has caused heartache and delays across the Atlantic with the ISABELLE project at Brookhaven National Laboratory, but probable success with the Tevatron at Fer- milab. DESY has two trial designs of 6-m magnets, a prototype of one of which has just begun tests. Six experimental magnets are under construction. All are, in fact, more similar to the Fermilab magnets than to ISABELLE's. Extended involvement in superconducting techniques will interest the French and Italian governments, DESY sources believe.

Robert Walgate - In the run-up to the election, Dr Heinz Riesenhuber also defined his position on other big projects: two, a giant spallation neutron source for low-energy materials studies and a deep crustal drilling project, have been shelved for decision "in 1985"; three, a new research reactor for the HahnMeitner Institut in Berlin, a new heavy ion cyclotron for Darmstadt, and a replacement for the research ship Meteor, will see decisions "within 12 months"; and two are already approved: an X-ray satellite ROSAT for the Max Planck Society, to start in 1987, and the large electronpositron collider LEP for CERN, Geneva, to which West Germany will contribute 25 per cent of the cost.
Landsat

\section{Future plans are up in the air}

Washington

THE cover picture of this issue showing Washington DC was generated by a new instrument carried aboard Landsat 4, the Thematic Mapper. Flying 438 miles above the Earth's surface, this instrument can pick out features with a resolution of $30 \mathrm{~m} \times 30 \mathrm{~m}-$ roughly one-quarter of an acre. Seven spectral bands, including a new middle-infrared band $(1.55-1.75 \mu \mathrm{m})$ sensitive to variations in vegetation moisture, and significantly narrower green, red and near-infrared bands, should provide more detailed information than that available from the Multi-Spectral Scanner flown on this and earlier Landsats.

The National Aeronautics and Space Administration (NASA)'s remarkable success with this new instrument, however, comes at a time when the future of the entire Landsat programme is very much up in the air. On 31 January, NASA transferred operation of Landsat to the National Oceanic and Atmospheric Administration

\title{
Earth as seen by polar orbiting satellite
}

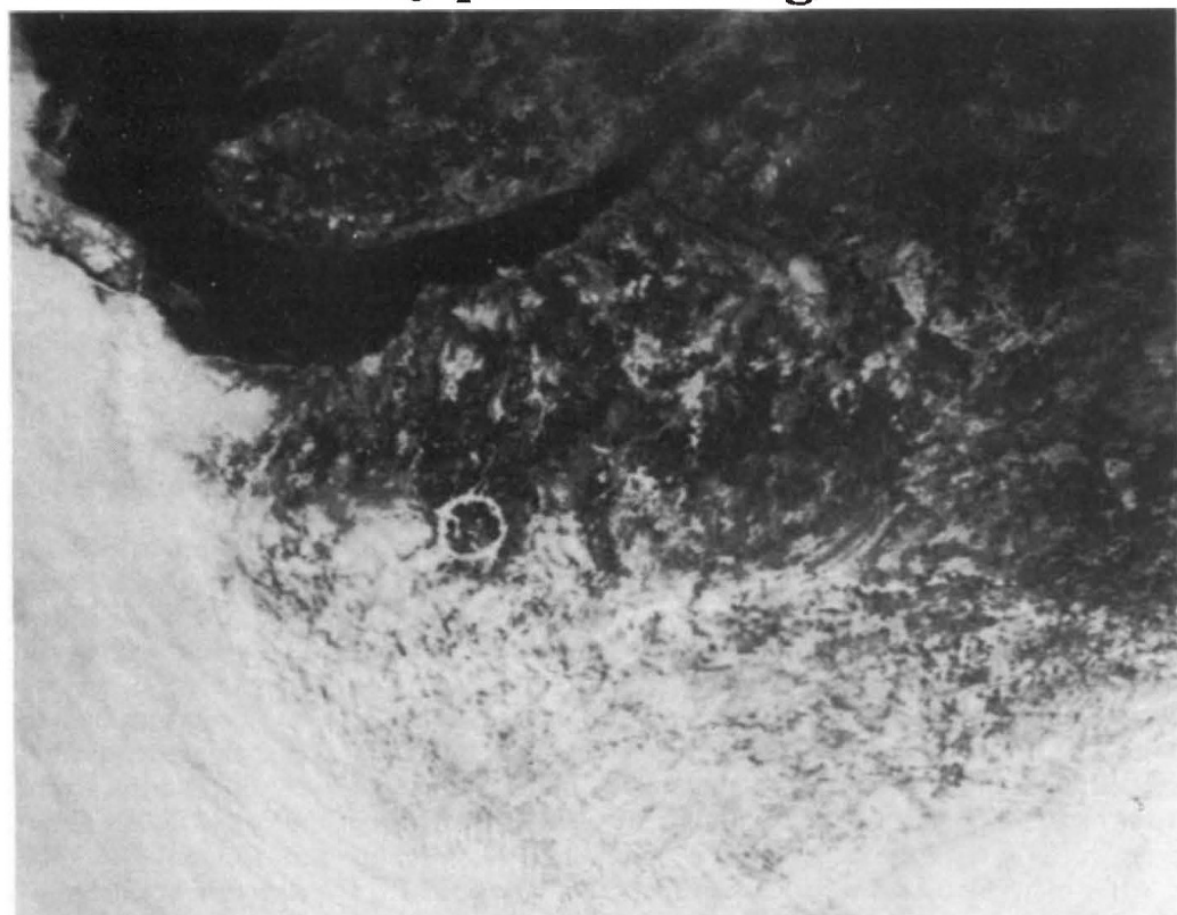

AN image taken by the satellite NOAA-6, a polar orbiting imaging satellite that monitors meteorological and oceanic phenomena with a resolution of $1.1 \mathrm{~km}$. Land features are also observable - in the picture can be seen the circular structure at Manicouagan, Quebec which is $65 \mathrm{~km}$ across, about 215 million years old, and thought by many to be an impact structure (but see also Nature 218,$457 ; 1968$ ).

Lying within Nature's London office are four large boxes of such photographs, ready to be removed by whoever would like them. An earth scientist at the UK's Open University asked the US National Oceanic and Atmospheric Administration (NOAALand Sciences Branch) for a sample computer tape of such images in digital form. Rewarded for his interest by the boxes of photographs, he passed them on to us. The boxes are voluminous and heavy, and we would welcome any proposal to put them to constructive use. Those interested should write to the Editor. 